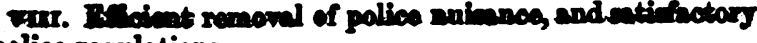
police regulations.

Ix. Bducation of cholere nunes, to be drafted from woxkhouses and public charities.

x. House to house visitation during epidemic cholera.

II. Frection of the cholern hospitals formerly allinded to*

Yurray's Royal Asylum, Perth, Norember 185t.

\section{CASE OF FRACTURE OF THE BASE OF THE SKULL: RECOVERY.}

By GEORGE BIDIE, M.B. and L.R.C.S.E.

Or Sunday, the 21 st of May, while visiting a patient in the country, I was hastily summoned to see a lad in the fohing village of Findochty, who had met with a serious accident. On my arrival, I learned that the sufferer, a young fisherman, aged 16 years, had been reclining upon the brink of a crag in the neighbourhood; and that, on getting up "to stretch himself", he had lost his equilibrium, and fallen down a height of from twenty to thirty feet. The head had first come in contact with the ground, and there was a deep ragged scalp wound stretching from right to left across the occipital protuberance. This gap had bled profusely; and on washing away the clots that hung in the hair, I discovered a copious hæmorrhage welling up from the left ear. The discovery of this hrmorshage, in conjunction with other signs indicative of serious mischief, led me to suspect fracture of the base of the skull-the fracture by contre-coup. To remove the more alarming symptoms of collapse was now my care-the pulse being very feeble and intermittent, and the heat of the body considerably below the natural temperature. In - little, frequent vomiting ensued; and I was gratified by seeing at any rate a partial recovery established. By this time, the bleeding from the ear had completely soaked the pillow. Taking, therefore, into account the aggregate loss of blood, I was led to consider further depletion unnecessary. No fracture could be detected at the site of the scalp wound, and the other parts of the body amenable to an outward examination seemed quite intact. I now cut the hair as close as possible, approximated the edges of the wound with strips of adhesire plaster, and had the head elevated upon pillows, with orders that it should be kept constantly covered with cloths wrung out of cold water. Before leaving for the night, I administered twelve grains of calomel rubbed up, as the power of deglutition was but feeble, in a pill of fresh butter.

Monday, May 22nd, 6 o'clock A.M. During the night, my patient had relapsed into a state of insensibility nearly as profound as the primary. The skin was hot and perspiring; the pulse slow, but rising upon any attempt being made to arouse him; the breathing was slow, deep, and somewhat stertorous; the bowels had been unmoved. One drop of croton oil was put upon the tongue, and an enema of turpentine ordered. The enema was directed to be repeated at intervals. A thin watery discharge had taken the place of the hæmorrhage from the ear.

7 o'clock P.x. The second enema had been administered about 12 o'clock at noon, and brought away large quantities of freal matter. Since then, the patient had twice intimated, by intelligible signs, a wish to have the chamber utensil when the calls of nature were urgent. Any attempt, however, to arouse him from the lethargy which still continued, merely tlicited a surly "be quiet", or a wish to be let alone. The pulse was still slow; the skin cooler; and the breathing freer.

May 23rd, 12 o'clock at noon. My friend, Dr. Gerrard of Buckie, kindly accompanied me during this visit, and formed the same opinion as myself regarding the nature of the injury and imminent danger of the patient. The stupor was still persistent; the pulse slow; the skin hot. He had spent a restless night. We ordered twelve

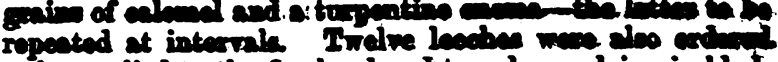
to bo applied to the forehead and temples, and ice in blact ders kept conntently upan the hoad

May 24th, 6 o'clock 4.X. The stuper was leas maked; the pulse had improred; and the borrell had been morect freely more than once. I ordened twelve powders, contrining in all twenty-four grains of calomel. Three of thees. powders were to be administered drily.

8 o'clock erening. He was ctill improving aince the morning.

From this date the pationt gradually progressed towands necovery, the treatment, with slight variations, being merely a repetition of the foregoing. The scalp wound healed kindly. During recovery he exhibited great wealmeese in the lower extremities, staggering like a paralytic on being aasisted to the erect posture. By the l0th of June, he could with a little assistance walk from his bed to a chair. For a time, however, after regaining the power of speech, his memory was completely upset. Iike some of the Athenians, who recovered from the great plague, mentioned by Thucydides, he actually could not at one period recallect his own name, or that of a single friend. The intelligent look, however, that his features displayed upon his being asked the name of any friend, seemed to indicate the power of recognition, although memory refused to supply the correct name, and furnished instead a nomenclature the most fantastic and inexplicable. His mother was frequently called "the tongs", "the book", etc.; and hardly ever by any chance did she twice enjoy the same appellative. Repeated blisters and a seton in the neck, along with the cautious use of mercury, shortly began, however, to effect a change; and by the middle of July, he was in perfect possession of all his faculties, physical and mental.

Cullen, December 4th, 1854.

\section{$\checkmark$ \\ CASE OF SUDDEN DEATH DURING THE INHALATION OF THE VAPOUR OF CHLOROFORM.}

By JOHN BIRKETT, Esq., Surgeon to Guy's Hospital.

HANNAH Brooks, aged 56 years, was admitted into Guy's Hospital, under my care, Nov. 15th, 1854. She said she was in good health; but she had a most cachectic appearance, was edentulous, and appeared quite ten years older than the age she represented herself to have reached. She lived in Southwark, and obtained a somewhat precarious livelihood by washing. She had had chronic ulceration of both legs the last two years, the ulceration nearly surrounding the leg, at about the junction of the middle and lower third. Two months before admission into Guy's, the ulcer on the left leg assumed a sprouting, fungating aspect, became very painful, and, during the last month, it bled frequently and profusely. In the left groin there was an enlarged gland. Various means having been ineffectually employed to destroy the cancer, amputation of the limb below the knee was proposed as the only palliative measure, and was agreed to. She drank some wine and water a short time before the administration of the chloroform. Her mind was calm and resigned, and there was no apparent depression produced by the contemplation of the operation. On Monday, the 4th of December, she seemed to be suffering from a trifling febrile attack, and said she thought she had taken cold. I told her that, if this condition existed upon the following day, we must postpone the operation. I gave her an ounce of mixture of acetate of ammonia, with fifteen minims of tincture of hyoscyamus, three times daily. On Tuesday, the 5th, she expressed herself as feeling quite well; the febrile attack had passed away; the skin, the temperature of which wes higher than the healthy standard the day before, was natural; and her tongue was slightly furred - a condition of this organ which had existed during the whole time of my observation of the case. A few minutes after 1 P.X., she was carried into the operating 